\title{
About orthostatic hypotension in tetraplegic individuals reflections and experience
}

\author{
Marc Maury \\ Honorary Chief Consultant of the Rehabilitation Centre of Fontainebleau, 24 Avenue de Suffren, 75015 Paris, France

\begin{abstract}
The author recalls the role of the autonomic nervous system and the means of investigation of this system in orthostatic hypotension occurring in tetraplegic individuals and the haemodynamic, biochemical and humoral changes which are triggered by upward tilting of such people. He then considers some of the problems that a person who is tetraplegic may encounter during his life. Regular follow up of each tetraplegic person is necessary and includes respiratory function tests as well as $24 \mathrm{~h}$ blood pressure monitoring.
\end{abstract}

Keywords: orthostatic hypotension; tetraplegia; long term quality of life

For a century a number of papers have been published on the various circulatory effects of autonomic dysregulation in certain individuals and experimentally in animal studies resulting from lesions of the spinal cord. ${ }^{1-6}$

Regarding specific scientific works devoted only to orthostatic hypotension $(\mathrm{OH})$ the first to be published was that of Hill in $1895^{7}$ followed by the report of Stead and Herbert ${ }^{8}$ in 1941.

In the normal situation, standing up normally requires haemodynamic and biochemical responses which depend greatly on the autonomic nervous system but also on the particular influence of cardiac (resistance and output), renal (baroreceptors), and vascular structures (e.g. concerning the pathology of old age). ${ }^{9}$

In those who are tetraplegic, the loss of vasomotor regulators in the extensive vascular pool in the lower limbs and in the splanchnic territory plays a major part regarding the onset of orthostatic hypotension $(\mathrm{OH})$ and these have been the subject of numerous publications mostly about autonomic hyperreflexia rather than about hypotension. It would be unfair in this article not to mention the important role of Mathias, who has been particularly involved with the topic of hypotension for more than 20 years. ${ }^{9-12}$

The haemodynamic, biochemical and humoral changes which are triggered by orthostatic forces may be summed up as follows:

(1) A reduction of the intra-thoracic and central blood volume (the absence of pumping effect from muscular contractions can also have some influence).

(2) A modest and delayed release of catecholamines already at a low resting level ${ }^{10,13,14}$ triggering off the renin-angiotensin system by the renal baroreceptors $11,13,14$
(3) Then, in the absence of a sufficient correction of the $\mathrm{OH}$, a release of $\mathrm{ADH}$ and eventually the onset of secondary hyponatraemia. ${ }^{15-18,20}$

It has also been shown that the osmoregulatory system functions normally in spinal injured patients and that hypokalaemia, more pronounced in those who are tetraplegic, co-exists with an increase of the volume of extra-cellular fluids and unstable hyponatraemia. This is also more pronounced in tetraplegic individuals. ${ }^{15,18}$ Moreover, the slowing of extent of the cerebral blood flow as shown by the transcranial Doppler technique, does not correlate with the data given by the tensiometer but with the clinical symptoms of $\mathrm{OH}$, demonstrating that the autoregulation of the cerebral blood flow is preserved. ${ }^{21}$

Although $\mathrm{OH}$ is common in those who are tetraplegic, it does not appear in every such individual. One may wonder why: An answer could be that incomplete lesions of the autonomic nervous system may exist, similar to incomplete motor and sensory lesions but we do not have the means of detecting these clinically. This is despite early twentieth century studies, in particular those of Dejerine on the systematization of the autonomic nervous system ${ }^{22}$ and in the studies of André Thomas on the pilomotor reflex, ${ }^{23}$ including studies during the phase of spinal cord automatism. $^{24}$ More recently Bonica has published an important work on the systematization of the nervous system and particularly of the autonomic nervous system. ${ }^{25}$

There is the possibility of interesting research, both clinical, based on these studies and those on autonomic evoked potentials to establish a protocol of autonomic nervous system examination; and secondly, anatomical-physiological, which would compare the protocol by fine detail imaging of the anatomical lesion. 
The autonomic lesion level could also be defined by micrographic recordings of sympathetic activity by means of skin electrodes placed over a branch of the peroneal nerve, ${ }^{26}$ and trials to determine the completeness or incompleteness of autonomic function have been conducted by registering potentials at the level of the soles of the feet in response to stimulation of the head. ${ }^{27,28}$

The situation might be clearer if there were longitudinal studies of orthostatic hypotension in tetraplegic individuals over a sufficient number of years. Lastly, it would be interesting to establish a collaboration with space medicine to detect and combat the effects of weightlessness, which necessitates the use of a pressurized space suit to compensate the lack of barometric pressure.

As publications are not only aimed at the selfgratification of their authors but also to help patients, I would like to bring up some points with regards to long-term life problems. Indeed, with the ageing process, the known difficulties increase and some others will appear.

\section{$\mathrm{OH}$ and changes of position}

Except in those individuals when tilting triggers off strong spasms which help the venous return, ${ }^{29}$ tilting upwards usually causes a more unpleasant $\mathrm{OH}$ than does the change to a sitting position probably due to the fact that the internal organs are more compressed and that a person who is tetraplegic can lean forwards somewhat when sitting.

The change from lying prone to lying on the side and vice versa can also cause fainting. This phenomenon may be connected to hypovolemia, but this does not yet appear to have been proven.

\section{OH and physical exertion}

In the early stages of rehabilitation, it is advisable to perform rehabilitation exercises in a lying position before gradually adapting to the sitting position. With persistent training the achievements possible are sometimes quite amazing especially concerning the field of sports. The adaptation period is longer if to the neurological $\mathrm{OH}$ is added the loss of cardiac adaptation to exertion which is related to myocardial atrophy caused by prolonged immobilisation. Hence the importance of performing exercises in bed during the initial period and avoiding prolonged periods in bed later in life. Whenever possible, a period of sitting is beneficial.

Sooner or later, the ageing process can interfere with the adaptation to exertion, causing functional losses in dressing, transferring and moving which may even require a return to longer resting periods in bed.

\section{$\mathrm{OH}$ and medications}

There are few medications which can alleviate $\mathrm{OH}$. Ephedrine has a limited effect and is frequently not tolerated. The benefits of Midodrine (Gutron) (r) have not been sufficiently proven.

Most of the medications which increase or cause $\mathrm{OH}$ are well known and include practically all of the antidepressants, sedatives, anaesthetics and antispasmodic drugs. The list is long and a small dose can suffice. But the tetraplegic person must be aware, when seeing his general practitioner, that morning fatigue due to $\mathrm{OH}$ can be mistaken for a symptom of depression and thus antidepressants may be wrongly prescribed.

A special mention must be made here of intrathecal Baclofen (r): several hundred pumps have been fitted to date including patients with lesions above T6 level. Although Baclofen (r), which lowers or suppresses muscle tone, also has a hypotensive as well as a respiratory depressant effect, there have not been, to our knowledge, any studies on the secondary effects, or even a mention of such effects in the manufacturer's instructions. Furthermore the users must be warned of the possible suppressant effect regarding erection and ejaculation. $^{30}$

A $24 \mathrm{~h}$ blood pressure monitoring, as well as respiratory function tests, should be performed before and after the initial installation of the pump. The dosage and the mode of administration of the product should only be adjusted after careful examinations, certainly in aged patients with lesions above T6 level.

\section{$\mathrm{OH}$ and surrounding temperature}

Exposure to heat often makes $\mathrm{OH}$ worse and the impaired thermal regulation associated with problems of blood pressure regulation delay the perception of modifications in body temperature. Adaptation to heat includes perspiratory mechanisms and the activation of the thermo-regulating perspiratory glands which are under the influence of the sympathetic nervous system.

Methods of prevention (ventilator, air-fans and airconditioner) and of intervention are well-known: wrist immersion in cold water and even better, repeated spraying of the trunk and upper limbs with water and if necessary the whole body.

Obviously, the excess temperature of the surroundings is better tolerated if the individual is in the lying position. The bath temperature has to be checked and ideally immersion should be in water at about $36-$ $36.5^{\circ} \mathrm{C}$.

Lastly, it may be worthwhile comparing some studies with those who have sustained severe burns suppressing a major number of skin receptors.

\section{$\mathrm{OH}$ and the intestinal functions}

It is well-known that the mesenteric circulation is normally greatly increased during digestion. Is the 
haemodynamic mobilisation thus caused by the increase in intra-abdominal blood volume sufficient to explain $\mathrm{OH}$ ? The mechanism has not yet been sufficiently explained. ${ }^{12}$

When a tetraplegic person suffers from postprandial hypotension the best advice for such an individual is to lie down for an hour after a meal. Defecation can also cause hypotension when it necessitates a strong push against the closed glottis (Valsalva manoeuver). $\mathrm{OH}$ will be worse if the defecation triggers, as a result of anal spasticity, a small transitory hypertensive episode which is always followed by a hypotensive reaction.

\section{$\mathrm{OH}$ and the urinary function}

The tetraplegic person must be informed about the risks incurred by urinary retention not only because of hypertension but also because of the cardio-vascular collapse brought on by rapid emptying of the bladder.

\section{OH and respiratory insufficiency}

We do not know if there is a direct link between the two, $\mathrm{OH}$ and respiratory insufficiency, but we do know that their effects combine in diminishing functional performances and activities.

Knowing that those who are tetraplegic with a complete lesion have paralysis of the abdominal, intercostal and some other respiratory muscles (depending on the level of the lesion), as well as, at times, possible thoracic retraction due to the lack of thoracic mobilisation in the acute and post acute phase, and knowing that the vital capacity in all humans diminishes progressively during the whole of life from the beginning of adulthood, respiratory function tests as well as $24 \mathrm{~h}$ blood pressure monitoring should be a part of the regular follow-up of every person who is tetraplegic. This would help to prevent infectious and mechanical pulmonary complications such as bronchitis, pneumonia and atelectasis, by, for example, signalling the need for more chest physiotherapy, a reduction in activity and the setting up of ventilatory assistance at home.

Therefore, we can see that the conditions of life for someone who is tetraplegic do not solely depend on the extent of sensory and motor deficit, completeness or level of the lesion but also on the extent of the autonomic nervous system lesion. For hypotension, simple solutions such as support stockings, a multiposition reclining electric wheelchair, coffee intake, ${ }^{31}$ restricted consumption of alcoholic drinks, and of hydrocarbonated food, ${ }^{32}$ high salt diet for hyponatremia and a corset, are not always sufficient (corsets are sometimes difficult to adjust as they should not restrict the breathing and should take into account abdominal distension which can vary from day to day).

To conclude: The success of long-term rehabilitation depends to a great extent on a healthy lifestyle, on the knowledge acquired during rehabilitation, on the ability and willingness to be in charge of one's life, and on the quality of support in the family community. It depends finally on the financial situation of each individual who is tetraplegic as he or she becomes more and more dependent. The management of the various aspects of care (skin, bladder, bowels, blood pressure, and breathing) incur inevitably round-the-clock attendance which is costly.

\section{Acknowledgements}

I wish to thank: Dr R Bodley, Stoke Mandeville Hospital; Mrs Liliane Binnie, Administrator of IMSOP and Dr P Dollfus for assistance with the translation.

\section{References}

1 Suh TH, Alexander L. Vascular system of the human spinal cord. Arch of Neurol and Psych, 1939; 41: 659-677.

2 Pollock JJ. Defects in regulatory mechanism of autonomic function in injuries to the spinal cord. J Neurophysiology 1951; 14: $85-93$.

3 Koster M, Bethelm J. Paroxysmal hypertension and hypotension in patients with spinal cord lesions. Acta Psychiatrica and Neurologica Scandinavica 1961; $347-368$.

4 Mertens HG. On circulatory regulation in patients with cervical cord lesions. Acta Neuro-chirurgica 1961; 7 (suppl): 402-408.

5 Maury M. Les manifestations neuro-végétatives dans les lésions médullaires. Presse Méd. 1966; 74: 1673-1678.

6 Guttmann L. Spinal Cord Injuries. Comprehensive Management and Research 1st ed. Blackwell Scientific: Oxford 1973; chapter 25 pp: $271-279$.

7 Hill L. The influence of the force of gravity on the circulation of the blood. In the Lancet Feb 9 1895; $338-339$.

8 Stead ER, Herbert RV. Postural hypotension: disease of sympathetic system. Arch Intern Med 1941; 67: 546-562.

9 Mathias CJ. Orthostatic hypotension, mechanisms and influencing factors. Neurology 1995; 45 (suppl 5): 56-11.

10 Mathias CJ et al. Plasma catecholamines, plasma renin activity and plasma aldosterone in tetraplegic man, horizontal and tilted. Clinical science and molecular medicine 1975; 49: $291-299$.

11 Mathias CJ, Christensen NJ, Frankel HL, Peart WS. Renin release during head-up tilt occurs independently of sympathetic nervous activity in tetraplegic man. Clincial science 1980; 59: $251-256$.

12 Mathias CJ. Postprandial hypotension. Pathophysiological mechanisms and clinical implications in different disorders. Hypertension 1991; 18:5: 694-704.

13 Guttmann L, Munroe AF, Robinson R, Walsh JJ. Effect of tilting on the cardiovascular responses and plasma catecholamine levels in spinal man. Paraplegia 1963; 1: 4-18

14 Corbett JL, Frankel H, Harris PJ. Cardiovascular responses to tilting in tetraplegic man. Jl. Physiol 1971; 215: 411-431.

15 Cardus D, McTaggart WG. Body sodium and potassium in men with spinal cord injury. Archiv Physical Med Rehabil 1985; 66: $154-159$.

16 Sved AF, McDowell FH, Blessing WW. Release of antidiuretic hormone in quadriplegic subjects in response to head-up tilt. Neurology 1985; 35: $78-82$.

17 Soni BM, Vaidyanthan S, Watt JWH, Krishman KR. A retrospective study of hyponatremia in tetraplegic paraplegic patients with a review of the literature. Paraplegia 1994; 32: 597 607.

18 Williams HH et al. Nonosmotic stimuli alter osmoregulation in patients with spinal cord injury. J Clin Endocrin Metab 1990; 71: $1536-1543$ 
19 Ohtomo Y, Meister B, Hokfelt T, Aperia AC. Coexisting NPY and $\mathrm{NE}$ synergistically regulate renal tubular $\mathrm{NA}+, \mathrm{K}(+)$ ATPase activity, Kidney International 1994; 45: 1610-1613.

20 Frisbie JH, Steele DJR. Postural hypotension and abnormalities of salt and water metabolism in patients with myelopathy Spinal Cord. 1997; 35: 303-307.

21 Gonzalez F et al. Auto regulation of cerebral blood flow in patients with orthostatic hypotension after spinal cord injury. Paraplegia 1991; 29: 1-7.

22 Dejerine-Séméiologie des affections du système nerveux. Masson, Paris 1914; vol. 2, 592 pages.

23 Thomas A. Le Réflexe Pilomoteur. Etude Anatome-clinique sur le Système Sympathique. Masson: Paris 1921; 242 pages.

24 Thomas A. Les moyens d'Exploration du Système Sympathique et leur Valuer. Rapport à la Vllème réunion neurologique Internationale Annuelle. Revue Neurologique 1926; 6: 786-928.

25 Bonica John-J. Applied Anatomy Relevant to Pain. In Bonica JJ, Loeser JD and WE Fordyce. (eds) The management of Pain. Lea and Febiger Philadephia: London, 1990; 2120 pages; $133-$ 156
26 Wallin G, Stjernberg L. Sympathetic activity in man after spinal and injury. Brain 1984; $107-183-198$.

27 Previnaire JG, Soler JM, Hanson P. Skin potential recordings during cystometry in spinal cord injured patients. Paraplegia 1993; 31: $13-21$.

28 Schurch B, Curt A, Rossier AB. The value of sympathetic skin response recordings in the assessment of the vesicourethral autonomic nervous dysfunction in spinal cord injured patients. The Jl of Urology 1997; 157: 2230 - 2233.

29 Bidart Y, Maury M. The circulatory behaviour in complete chronic paraplegia. Paraplegia 1973; 11-24.

30 Denys P. Personal communication.

31 Robertson $\mathrm{D}$ et al. Effects of cafeine on plasma renin activity, catecholamines and blood pressure. N. England Jl Med 1978; 298: $181-186$.

32 Berne C, Fagius J, Niklasson F. Sympathetic response to oral carbohydrate administration, Evidence from microélectrode nerve recordings. J Clinical Invest, 1989; 84: 1403-1409. 